\title{
Correction to: Electrical conductivity of tremolite under high temperature and pressure: implications for the high-conductivity anomalies in the Earth and Venus
}

\author{
Kewei Shen ${ }^{1} \cdot$ Duojun Wang ${ }^{1} \cdot$ Tao Liu $^{1}$
}

Published online: 13 April 2021

๑) Springer-Verlag GmbH Germany, part of Springer Nature 2021

\author{
Correction to: \\ Contributions to Mineralogy and Petrology (2020) \\ 175(5):52 \\ https://doi.org/10.1007/s00410-020-01688-y
}

In the original version of this article, the Fig. $8 \mathrm{~b}$ was displayed incorrectly. The corrected Fig. $8 \mathrm{~b}$ is shown in this correction.

Publisher's Note Springer Nature remains neutral with regard to jurisdictional claims in published maps and institutional affiliations.

The original article can be found online at https://doi.org/10.1007/ s00410-020-01688-y.

Duojun Wang

duojunwang@hotmail.com

1 Key Laboratory of Computational Geodynamics, College of Earth and Planetary Sciences, University of Chinese Academy of Sciences, Beijing 100049, China 


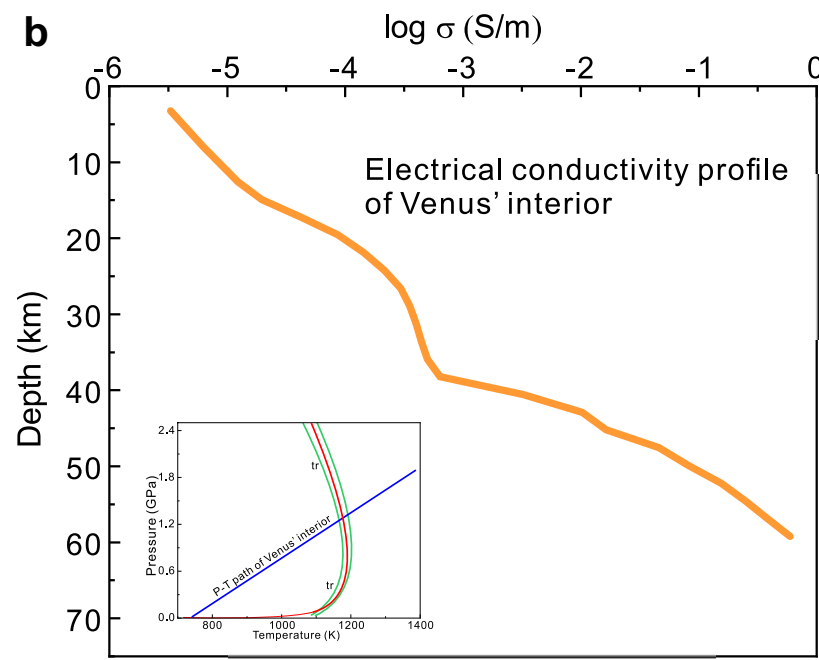

Fig. 8 b Tremolite conductivity variation with depth, superimposed on the thermal structure and P-T path of Venus' interior (Aitta 2012) and the tremolite stability data (Welch and Pawley 1991; Jenkins 1991) 